\title{
The Application of Methods for Creative Development of Personalities in Natural Sciences in Studying Foreign Languages for Specific Purposes
}

\author{
Roksolyana Shvay ${ }^{1}$, Nataliya Morska ${ }^{2} \&$ Bohdan Kalynyak $^{3}$ \\ ${ }^{1}$ Institute of Jurisprudence, Psychology and Innovative Education, Lviv Polytechnic National University, Lviv, \\ Ukraine \\ ${ }^{2}$ Institute of the Humanities and Social Sciences, Lviv Polytechnic National University, Lviv, Ukraine \\ ${ }^{3}$ Department of Mechanics of deformable bodies, Pidstryhach Institute for Applied Problems of Mechanics and \\ Mathematics, National Academy of Sciences of Ukraine, Lviv, Ukraine \\ Correspondence: Bohdan Kalynyak, Department of Mechanics of deformable bodies, Pidstryhach Institute for \\ Applied Problems of Mechanics and Mathematics, National Academy of Sciences of Ukraine, Lviv, Ukraine. 3b \\ Naukova St., 79060, Lviv, Ukraine.
}

Received: December 9, 2020

Accepted: December 28, 2020

Online Published: January 4, 2021

doi:10.5430/ijhe.v10n3p119

URL: https://doi.org/10.5430/ijhe.v10n3p119

\begin{abstract}
This investigation proposes to apply the methods of training creativity in the natural sciences to teaching a foreign language for specific purposes. This approach is based on the testing of foreign language competencies in different countries, on the task of training higher education specialists, including foreign language training, on the requirements for learning foreign languages, formulated by the European institutions, and on the requirements for specialists in EU. The methods of teaching creativity of specialists in the natural sciences are based on Molyako's (2008) five strategies of creative design activity. Their practical application demonstrated in teaching physics has been used in teaching English for specific purposes. The analysis of the results of the application of the proposed methods was carried out based on a questionnaire by Popek (2000), which allows differentiating persons with creative aptitudes. The results of the analysis indicate the feasibility of applying the proposed methods for the creative development of personalities following the needs of modern social relations, focused much more on synthesis and interconnection than on the analysis of individual phenomena and processes.
\end{abstract}

Keywords: creativity, foreign language for specific purposes, English, CARUS method

\section{Introduction}

Ways of thinking, attitudes, values, and other personal qualities that determine a person's ability to successfully socializing, to engaging in professional and educational activities are increasingly important in the context of rapid changes in human-environment interaction, interpersonal relationships, due to the rapid development of technology, particularly in communications.

Learning outcomes depend on many factors. Individual understanding of the learning material by the student is connected with characteristics of thought, memory, individual mental processes, differences in abilities to act, etc. The creative teacher organizes the cognitive activities of students in a way to prepare them to be ready for gradually transferring his managerial functions. The learning takes priority over teaching, the process of thinking (how to think) is over content (what to think). Helping to understand and to grow his personality, to find new ways of his growth, to affirm the value of his work and its outcomes, to encourage his imagination, to develop creativity is the best thing a teacher can offer to his student.

An important motivation of the teacher is the professional desire for the development of students, the pleasure of communicating with them. This requires methodical creativity from the teacher, which we interpret as activities aimed at improving the content, the organizational modes of education, the search of non-standard organizational systems of teaching and the methods of students' professional development and their introduction.

Achieving high learning outcomes is impossible without learning the language as a means of sharing information between people in the broadest sense: communicative, cultural, social, logical, scientific, etc. Requirements for 
education expressed by employers in Davos (World Economic Forum [WEF], 2015, 2017), foreign language learning documents in (Council of Europe, 2001), IESL type tests, TOEFL (British Council, 2020a, 2020b; ETC, 2020) lead to some conceptual methodical guidelines for studying the English language for specific purposes, which contribute to the development of technical, mathematical and design competences under the profile of a technical university.

The basis for the study of the possibility of applying the methods for the creative development of personalities in the natural sciences in foreign language classes for specific purposes were the current opinions and regulations on the study of foreign languages in the EU (Council of Europe, 2001), tests of foreign languages of European institutions (British Council, 2020a, 2020b), opinions on competences (WEF, 2017, 2018) to be provided by modern education, foreign language working programs of higher education institutions of Ukraine (Bolitho, 2017), the development of natural sciences and the problems to be solved by engineers and scientists in the field of natural sciences, didactic application of the theory of creativity in education (Shvay,2019).

\section{The Task of Education and Learning a Foreign Language. European Vision}

The system of education is dependent on the economic and cultural state of the country. In the Davos Business Forums reports (WEF, 2015, 2017) industrial needs and corresponding education requirements for successful job placement for the participants of the education process have been analyzed. In particular, the key characteristics of an educated person in the 21st century (WEF, 2017) should be critical and creative thinking, communication skills, collaboration. A competent person should possess the following knowledge and skills:

- for the year 2018 (WEF, 2018): innovation and analytical thinking, comprehensive solving a problem, critical thinking and analysis, strategies of active learning, creativity, originality and initiative, attention to detail, reliability, emotional intelligence, understanding problems and ideas for their solving, leadership and social influence, coordination and time management;

- for the year 2022 (WEF, 2018): originality and initiative, the technology of designing and programming, analytical thinking, system analysis, innovation, active learning strategies, and active learning, creativity, critical thinking, solving of the comprehensive problem, emotional intelligence, social influence, leadership, understanding problems, and ideas for their solving.

In these documents priorities were also given to the reducing of the importance of such competencies of employees by 2022 as manual dexterity, endurance and verbal accuracy, auditory and spatial abilities, handling of financial, material resources, memory, active listening, reading, writing, and maths, HR, installation and maintenance technology, coordination and time management, visual, auditory and speech abilities, use of technology, quality control, and safety awareness, monitoring, and control.

Thus, analytical thinking, emotional intelligence, creativity, and active learning tend to become more important in education with a tendency to decrease the requirements of acquiring purely professional competencies.

For the development of these competencies, we propose to implement the methods of engineering and technical creativity in the process of teaching a foreign language for specific purposes for students of technical specialties. One of such methods is the CARUS method (Molyako, 2008).

\section{Method. Strategies and Tactics for Development of Creativity}

Heuristic programs and methods of development of creativity, methods of solving problems stimulate intuitive thinking, finding effective strategies for solving problems (Altshuller, 1973; Bono, 1976; Feldhusen, Speedie, \& Treffinger, 1971; Góralski, 2010; Joseph, 2009; Osborn, 1993; Nęcka, Orzechowski, Słabosz, \& Szymura, 2019; Ponomarev, 1976; Polya, 1971,1981).

V. Molyako (2008) used the concept of "creative potential", encompassing abilities, talents, and genius, i.e. the whole spectrum of human creative potential. Specific components of creativity, such as general intelligence, interests, intuition, personal strategies, and problem-solving tactics, include creativity, such as the ability to combine, find analogies, reconstruct, the propensity to change options, the rational use of tools, etc (Molyako, 2008, p. 7). Among the structural elements of creativity it is necessary to distinguish: the ability to reconstruct, find analogies, the ability to think outside the box, and behavior. The expression of creative potential (Molyako 2008, p. 73) is determined by the following criteria:

- multivariate number of options for solving the problem

- ingenuity, in particular, as the speed of solving the task

- originality as a reflection of the identity of the person who solves the problem. 
The technique of CARUS deals with improving the structure and functions of the design of elements by implementing such fundamental strategies as combinatorial behavior, the search of analogs, reconstructions, universal strategies, random substitutions, and tactics such as interpolation, replication, multiplication, convergence, deformation (transformation and integration of basic data, autonomy, animation, convergence, deformation) in the technological imagination.

For creative design activity V. Molyako (2008) outlined five main strategies, namely:

I - combinatorial actions (combination strategy)

II - search for analogs (analogy strategy)

III - reconstructive actions (reconstructing strategy)

IV - universal

$\mathrm{V}$ - random substitutions.

I. The strategy of combinatorial action involves the joint use of a variety of mechanisms to create a new design. The strategy is connected to various permutations, reduction, and increasing in size, changing the location of parts in the existing structure.

II. The technique of searching for analogs requires the use of an installed structure or of its part in another role by the manufacturing or designing a new device. Anything fresh or used under new circumstances must be transmitted. The development of a new design may be associated with analogs in nature.

III. The strategy of restoration is related to restructuring (with an antagonistic nature) or more specifically, reversing. A steel, for example, may be replaced by a composite one and so on. We may conclude that renovation, distinct from what was used earlier, is the most creative approach to finding a completely new one. The scope of creativity here, of course, will also be another: It is possible to change only one element in the device and restore its entire architecture entirely.

IV. The relatively uniform use of comparison, merging, and to some extent, reconstruction is associated with a universal approach. It is an alternative where the mixture of acts is such that the gain of one of them is difficult to highlight.

V. The method of random substitution. There are situations where it is usually difficult to ascertain the essence of the behavior of the subject at all, where there is no dominant pattern and the quest is carried out blindly, without a strategy, or at least neither the subject itself nor the outside observer can depict any rational relations.

The mentioned above strategies may be used by the acts of synthesis or analysis.

The use of unfavorable situations for education, coaching is an essential feature of the CARUS system. Several special methods have been developed for this purpose:

1. The purpose of the method of time constraints is to use mental activity to achieve the goal in a limited time. If the subject is not interested in the time of the solution of the task, he has time to plan his actions in details, to check some approaches for solving the problem, as well as its quality.

With time constraints, decisions can usually be simplified because the subject is limited to using what he or she knows best of all (for the most part this is a template variant), or the decisions are modified to some extent. The general tendencies of human mental activity can be determined by the type of these modifications. People respond differently to time constraints. Some of them cause increased activity and even higher results, while others change their behavior in different ways, lowering results and not always achieving the aim. Time constraints have a braking, startling impact for some people that give rise to hesitation, fear, and rapid rejection of tasks.

2. The method of sudden bans (MSBs) is to ban certain mechanisms at one stage or another. It destroys assumptions, avoids the use of different types of equipment, elements, pieces. Thus professional designers naturally form certain styles of activity, during which they use certain techniques, specific mechanisms. Therefore this approach is also very successful. Using MSBs will contribute to destroy styles of activity. Applying this method allows us to reveal habitual, formed tendencies of activeness, and also trains us to change the activity to concrete circumstances.

3. The method of speed sketching is aimed at determining a characteristic of mental activity. It may be suggested to continually 'draw' the thought process that depicts all constructions that come to mind. It leads to better control of their operations, regulating the creative process through images. The use of this method makes possible more precise transformations of the images, identifying the values that correspond to the concept and visual representation of a 
specific structure.

4. The method of new options is the requirement to solve the problem differently, to find new solutions. It always causes the power to be further activated, aiming at a creative solution to the problem. This technique is applicable at any stage, even before the subject has found a solution (in the sketch version). Then this method can also become a kind of method of sudden bans.

5. The lack of information method is applied when the task of special activation of the activity in the first stages of the decision is used. In this case, the initial condition of the problem is presented with a significant lack of data needed to start the decision. Thus, one or the other task may lack the important characteristics of the input data, for example, structure, flow characteristics, rotational speed, environment characteristics, etc. Using different modes of presentation of the initial condition is an important modification of this technique. You can deliver start-up tasks that are viewed as graphics or text only. It can be effective in learning the features of understanding, in identifying an available stock of knowledge.

6. The oversaturated information approach includes a piece of unnecessary information in the initial state of the task. A variation of this approach is an oral tooltip about redundant data that can be diverted only from valuable knowledge. It is up to the teacher to determine how to implement this method: he or she may recommend selecting the appropriate information or not to claim that there is an excess of information in the situation.

7. The technique of the absurd is to propose an unsolvable problem. A common variant of absurd tasks is the creation of an everlasting generator without an outer energy supply. The bizarre, incredible tasks may be also discussed, for example using mouse power for obtaining the electricity supply in the flat. It lets you cope with existing habits of thought and get creative with your tasks.

8. The approach of situational dramatization is that such modifications are made in the course of the decision, depending on the particular pedagogical strategy and the process of the task. These modifications are intended to complicate the operation and can vary from concerns raised by the instructor ('obstruction issues') to different questions not needed by the normal procedure requirements. The sudden method of prohibition is a modification of the method of situational dramatization. The mentioned above methods may be combined with other ones and have different modifications.

\section{Results. Implementation of Methods for Creative Development of Personalities in the Practice of Teaching Foreign Language for Students of Technical Specialities}

Let us consider the possibility of using the basic provisions of the CARUS method in the process of teaching a foreign language for specific purposes in higher technical schools, where the development of creativity is an important component of training engineers, designers of new equipment, etc. The basis for the creation of such foreign language assignments were samples of exercises (Góralski, 2010) and problems in physics developed and tested (Shvay, 2007, 2011).

Examples of such tasks are:

- To increase the creative imagination exercises for "creating new concepts" were proposed. Students are encouraged to invent the name of an entity that doesn't exist and describe it in their own words. The same should be done in your mother tongue. It is possible to offer a concept in a mother tongue that is not used in English and explaining it in the light of the specificity of English culture. The verbal justification for choosing a particular association or chain of associations in a foreign language is important.

- The exercise of "creating 'star' associations" is directed to find many associations with the given concept and corresponding with it.

- Exercise "observing the world's diversity" is developed to increase the apprehension of the environment beyond the artificial constraints created by us. The necessity of these exercises is in destroying the stereotypes of perception in different educational circumstances formed by solving standard tasks and to form student's worldview focused on personal communication with nature, a part of which we are.

- The "thousand definitions" exercise. The exercise is intended for the development of imagination and the ability to abstract due to the definition and redefinition of concepts. To create a large number of definitions of known objects and phenomena, one must first identify their similar characteristics by using an abstraction operation. It is proposed to create a new definition of the concept in the form “... is ... because...". Arguments can be banal, irrational. Definitions should not contain obvious features, but new ones that rarely appear or are either implicit or can be modified. The exercise should be continued until unusual definitions 
appear, based on abstract attributes. Then the inverse task should be suggested, that is, guess the object by its unusual definition.

Table 1. Exercises for the development of creativity in the process of teaching physics and a foreign language

\begin{tabular}{ll}
\hline Exercise & Exercises in physics \\
\hline $\begin{array}{l}\text { Search for } \\
\text { analogs }\end{array}$ & Find a similar thing between the elements of \\
& the given set: fuel, the Sun, ray, pendulum, \\
& ultrasound scanner, balloon, mechanical work, \\
& compressed spring, the athlete jumps into the \\
& water (answer - energy);
\end{tabular}

Creating remote associations

Creating a chain of associations

Observing the diversity of the world and relationships between people

The thousand definitions

How can I use it?
Electron - gas discharge, electron - electric current, electron - electric heating devices, light beam - a mirror, lens - eye, light beam a solar eclipse.

Electron - atomic structure - electric current heating devices - human safety when working with electric heating devices - safety when working with household appliances - the safety of nuclear power plants;

Pressure - atmospheric pressure measurement - manometer - barometer navigation of vessels - blood pressure - health - life - future;

Magnetic field - permanent magnets electromagnets - electric motors - car;

For example, a lens is like glass because it transmits light.

What does the phrase "I feel warm" mean?

Where does the water disappear if it is in an open container?

How do you understand the phrase "I was hit by an electric shock"?

The lens is like glass because it transmits light.

The density of matter is as mass as it is the mass of volume unit of substance.

Suggest ways to use a particular measuring device to find different physical quantities.
Exercises in a foreign language

Give examples of certain surfaces, body parts of plants, animals, insects, etc, found in architectural structures (for students of architecture), (answer - wheat stalk in skyscrapers, a leaf in shell structures) design of mechanical components in machinery construction just as it is done in nature for students of mechanical specialties) (answer: mosquito proboscis - syringe needle; bird's wing - sail) using the experience of teaching students in the specialty.

Building - time, building - decor, building - purpose, building - architectural style; stick - prop, stick - lever, stick - cleaning; music - an instrument; music - voice; music is air; music is a thread.

Rain - spring - heat - birds singing - end of a pandemic summer vacation - happiness;

Health - desire to learn - positive emotions - success new achievements - development - new job - happiness creativity;

Architecture - style - structure - comfort - ecology;

Lens - eye - see - live - create;

Canvas - brush marks - portrait - recognition;

For example, a lens is like glass because it transmits light.

What does it mean to "enjoy what is seen or done"?

Is it possible to jump down from the windowsill of the tenth floor and stay intact? (answer: jump towards the room)

How do you understand the phrase "I was hit"?

Light is like medicine because it affects health.

Increasing space is like deceiving our sensations through light.

You can use the left-hand question for students of electrophysical specialties in English classes.

Suggest ways to measure the length of a room without the usual ruler (meter). What can be taken as a unit of length? (linear dimensions of pen, matches, pencil).

Suggest ways to use the cord to build a right angle, circle, mark a straight line on the wall.

Examples of exercises in physics (Shvay, 2011) and the developed tasks in a foreign language were provided in Table 1. 


\section{Discussion}

The research of learning English (assessment of students' knowledge of foreign language and assessment of the level of creativity) was carried out to check the efficiency of the implementation of methods for the creative development of personalities in the process of teaching foreign language for students of technical specialties. In total 89 first-year students of Lviv Polytechnic National University were enrolled in the experiment. In the control group the training was carried out traditionally according to the requirements, and in the experimental group with the application of the developed tasks and the introduction of methods for the development of creativity. Training with the use of adverse conditions was not used in experimental groups. Popek's (2000) questionnaire was used to study the level of students' creativity, features of their cognitive and character areas.

The concept of the questionnaire is based on the fact that the creative personality is characterized by two spheres: cognitive and character. The cognitive sphere is related to the instrumental capacity of the individual, that is, vulnerability, ability to observe (perceptual abilities) and to memorize, and, most importantly, to the transformation and creation of new information through imagination, intuition, and divergent thinking, that is, heuristic behavior. The algorithmic behavior of a person, which is characterized by a convergent type of thinking is opposite to the heuristic one in the questionnaire. Each measured quantity is dynamically interpreted as a continuous fracture (continuum), so both extremes, algorithmic and heuristic behavior, are equally important, although the creative personality has a fundamental dominance of heuristic behavior over algorithmic ones.

The second sphere is formed by a group of character traits that provide active self-realization of human potential. Effective self-realization of cognitive aptitudes, special abilities of the person depends on other characteristic features of the person conditionally defined as a non-conformal or conformal organization.

Conformity is characterized by the following features: dependence, passivity, stereotype, tolerance, weakness, intimidation, subordination, dependence, internal disorganization, excessive inhibition, focus on protection, small resistance, and endurance, irresponsibility, lack of criticism, lack of tolerance, underestimated sense of the meaning of "I".

Nonconformism is characterized by opposing features, namely: independence, activity, flexibility, self-organization, courage, self-consistency, spontaneity, expression, openness, endurance, responsibility, self-criticism, high sense of the meaning of "I". Algorithmic behavior is defined as reproductive orientation, controlled observation, mechanical memory, reproductive imagination, convergent thinking, reproductive learning, logical understanding and analysis, intellectual rigidity, cognitive passivity, low level of reflexivity, insignificant skills to transform, and to design, lack of technical ingenuity.

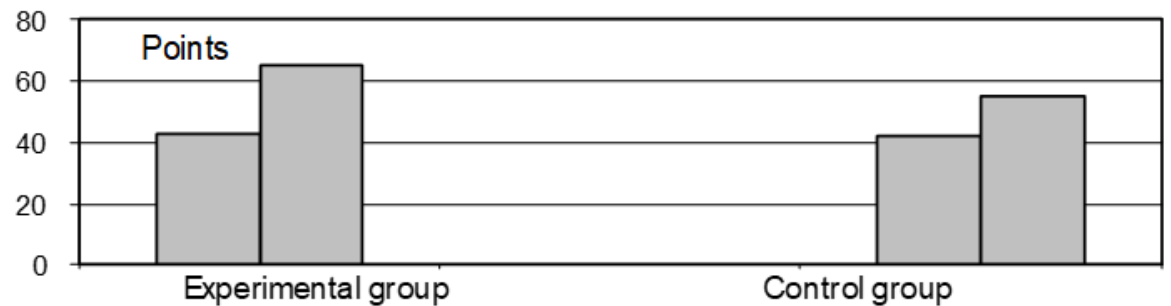

Figure 1. Increasing in the level of study results in the experimental group and the control group during the year (100 point scale)

Heuristic behavior is characterized by such features as self-observation, logical memory, imagination, divergent thinking, reconstructive and self-directed learning through reasoning, intellectual flexibility, cognitive activity, reflection, intellectual independence, constructive and verbal creativity.

Conformity - nonconformity, algorithmic behavior - heuristic behavior forms opposite poles of results, and therefore the obtained results are investigated separately.

The presence of reproductive or creative behavior is determined by the sum of $\mathrm{C}+\mathrm{A}$ (conformity + algorithmic behavior) or $\mathrm{N}+\mathrm{H}$ (nonconformity + heuristic behavior).

Thus the sub-tests of nonconformity and heuristic behavior predominantly determine the characteristics of creative people, and the scales of conformity and algorithmic behavior form a continuum opposite to creative activity.

A person's belonging to a particular group can be asserted based on the predominance of scores on one or another scale. 
The application of this method to assess the level of creativity of students allows for dynamic analysis of two areas (cognitive and characterological) of future engineers of technical specialties (technical aspect) in foreign language classes (humanitarian aspect).

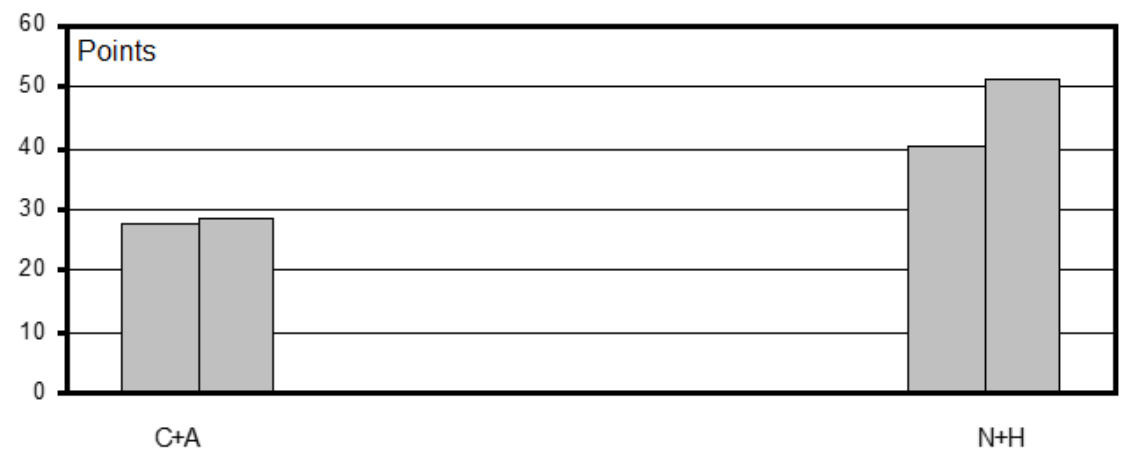

Figure 2. Increasing creativity growth using Popek's (2000) questionnaire among the first-year students at the beginning and the end of the academic year

Investigations have shown not only an increase in the level of knowledge of students in a foreign language but also an increase in their level of creativity, which is important for engineers of technical specialties. (see Figures 1,2).

\section{Conclusions}

Development methods of creativity, in particular the CARUS method, can be successfully used in foreign language classes for specific purposes to enhance learning outcomes and as a means of generating technical thinking. The use of separate strategies of the CARUS method becomes an incentive to improve psychological stability, initiative, emotional intelligence, understanding their strengths and weaknesses, professional ability to prepare for the tests of various levels.

A brief and accessible presentation of technology and scientific output and development is the minimum that a student can obtain for his continued successful work and with oral and written communication with foreign colleagues. From this point of view, the methods of creative development of personalities, in particular CARUS, can be implemented in the training process not only for the formation of creativity of specialists of technical specialties but also for their proficiency in a foreign language. It contributes to the complex formation of personalities under the needs and trends of the development of modern social relations oriented today more to synthesis and interconnection than to the analysis of particular phenomena and processes, instead of different subjects of study.

The requirements for assessing English language skills in the EU, based on an activity-based approach, are also broad but not universal consensus, allow for greater freedom in the choice of assessment criteria and teaching methods and provide their development. Using indirect tests indicates that such an assessment requires specific training. A cursory study of evaluation of the IELTS case indicates that several requirements are aimed at assessing the ability to articulate one's opinion clearly, highlight the key in context, and draw conclusions where an appropriate level of language proficiency is a means. Similar tasks in the natural sciences, in the technological processes, are obtained by specialists in technical specialties in foreign language classes. The shift of emphasis in teaching a foreign language to the expression of the same thoughts in different ways also contributes increasing competence in the natural sciences and can be an incentive for the creation of new ideas, the development of creativity.

\section{References}

Altshuller, G. S. (1973). Algorithm of Invention. Moscow: Worker Publishers [in Russian].

Bolitho, R., \& West R. (2017). Internationalisation of Ukrainian universities: the English language dimension. Kyiv: British Council. Retrieved from https://www.britishcouncil.org.ua/sites/default/files/2017-10-04_ukraine_-_repo rt_h5_en.pdf

Bono, E. de (1976). Teaching Tinking. London: Temple Smith.

British Council. (2020a). Free IELTS practice tests. Retrieved June, 2020, from https://takeielts.britishcouncil.org/prepare-test/free-practice-tests

British Council. (2020b). Understand the IELTS test format. Retrieved June, 2020, from https://takeielts.britishcouncil.org/prepare-test/understand-test-format 
Council of Europe. (2001). Common European Framework of Reference for Languages: Learning, teaching, assessment (CEFR). Cambridge University Press. Retrieved June, 2020, from https://rm.coe.int/1680459f97

ETC. (2020, June) TOEFL Go! Official App. Retrieved June, 2020, from https://www.ets.org/toefl/test-takers/ibt/prepare/app

Feldhusen, J., Speedie, S., \& Treffnger, D. (1971). The Purdue Creative Tinking Program: Research and Evaluation. Performance Improvement, 10(3), 5-9. https://doi.org/10.1002/pf.4180100304

Góralski, A. (2010). Rules for training creativity. Warsaw: Wydawnictwo Akademii Pedagogiki Specjalnej [in Polish].

Joseph, E. (2009). Effectiveness of Khatena Training Method on the Creativity of Form Four Students in a Selected School. Kuala Lumpur: University of Malaya.

Molyako, V. (ed.). (2008). Psychological study of the creative potential of the personality. Kyiv: Naukova Dumka [in Ukrainian].

Nęcka, E., Orzechowski, J., Słabosz, A., \& Szymura, B. (2019). Creativity training. Sopot: Smak Słowa.

Osborn, A. (1993). Applied Imagination. Principles and Procedures of Creative Problem-Solving. Buffalo: Creative Education Foundation.

Polya, G. (1971). How to Solve it: A New Aspect of Mathematical Method (2nd ed.). New Jersey: Princeton University Press.

Polya, G. (1981). Mathematical Discovery. On Understanding, Learning and Teaching Problem Solving V.'s 1-2. New York: John Wiley, \& Sons.

Ponomarev, Ya. A. (1976). Psychology of Creativity and Education. Moscow: Pedagogy [in Russian].

Popek, S. (2000). KANH creative behavior questionnaire. Lublin: UMCS [in Polish].

Shvay, R. (2007). Learning the art of solving problems in preparation for creative work. Collected scientific papers of Kamyanets-Podilsky State University: Pedagogical series: Didactics of physics and textbooks of physics (astronomy) in the conditions of formation of the European space of higher education, 13, 60-63. [in Ukrainian]. https://doi.org/10.32626/2307-4507.2007-13.60-62

Shvay, R. (2011). Didactic material in physics for training students' creativity. Grades 7-8. Tutorial. Lviv: Liha-Press [in Ukrainian].

Shvay, R. (2019). A Didactic Application of the Theory of Creativity in School Education. Prima Educatione, 3, 27-38. https://doi.org/10.17951/pe.2019.3.27-38

World Economic Forum. (2015). New Vision for Education. Unlocking the Potential of Technology. Retrieved June, 2020, from http://www3.weforum.org/docs/WEFUSA_NewVisionforEducation_Report2015.pdf

World Economic Forum. (2016). What are the 21st-century skills every student needs? Retrieved June, 2020, from https://www.weforum.org/agenda/2016/03/21st-century-skills-future-jobs-students/

World Economic Forum. (2017). New Vision for Education: Fostering Social and Emotional Learning through Technology. Retrieved June, 2020, from http://www3.weforum.org/docs/WEF_New_Vision_for_Education.pdf

World Economic Forum. (2018). The Future of Jobs Report 2018. Insight Report. Centre for the New Economy and Society. Retrieved June, 2020, from http://www3.weforum.org/docs/WEF_Future_of_Jobs_2018.pdf

\section{Copyrights}

Copyright for this article is retained by the author(s), with first publication rights granted to the journal.

This is an open-access article distributed under the terms and conditions of the Creative Commons Attribution license (http://creativecommons.org/licenses/by/4.0/). 